Full Paper

\title{
Electrochemical Synthesis and Characterization of 1,2-Naphthaquinone-4-Sulfonic Acid Doped Polypyrrole
}

\author{
Richard Odunayo Akinyeye, ${ }^{\mathrm{a}}$ Immaculate Michira, ${ }^{\mathrm{a}}$ Mantoa Sekota, ${ }^{\mathrm{a}}$ Amir Al Ahmed, ${ }^{\mathrm{a}}$ Duarte Tito, ${ }^{\mathrm{c}}$ \\ Priscilla Gloria Lorraine Baker, ${ }^{\mathrm{a} *}$ Christopher Michael Ashton Brett, ${ }^{\mathrm{b}}$ Maher Kalaji, ${ }^{\mathrm{c}}$ Emmanuel Iwuoha* \\ a Sensor Research Laboratory, Department of Chemistry, University of the Western Cape, Bellville 7535, South Africa \\ *e-mail eiwuoha@uwc.ac.za; pbaker@uwc.ac.za \\ b Department de Quinica, Universidade de Coimbra, 3004-535 Coimbra, Portugal \\ c School of Chemistry, University of Wales, Bangor LL572UW, UK
}

Received: July 10, 2006

Accepted: November 21, 2006

\begin{abstract}
Polypyrrole thin film microelectrodes prepared from an aqueous solution of the sodium salt of 1, 2-napthaquinone-4sulfonic acid and pyrrole in hydrochloric acid as the supporting electrolyte was characterized electrochemically for the first time and found to exhibit good electronic and spectroscopic properties. Voltammetric investigations showed that the polymer exhibited quasireversible kinetics in a potential window of $-400 \mathrm{mV}$ to $700 \mathrm{mV}$, with a formal potential of $322 \mathrm{mV}$ vs. $\mathrm{Ag} / \mathrm{AgCl}$. The diffusion coefficient was calculated to be $1.02 \times 10^{-6} \mathrm{~cm}^{2} \mathrm{~s}^{-1}$ for a thin film with a surface concentration of $1.83 \times 10^{-7} \mathrm{~mol} \mathrm{~cm}{ }^{-2}$ having a rate constant of $2.20 \times 10^{-3} \mathrm{~cm} \mathrm{~s}^{-1}$ at $5 \mathrm{mV} \mathrm{s} \mathrm{s}^{-1}$. Electrochemical impedance spectroscopy provided quantitative information about the conductivity changes within the modified polymer and support for the quasireversible kinetics suggested by voltammetry. The changes in electrical properties of the polymer during electrochemical p-doping and n-doping were quantified by equivalent electrical circuit fitting and assisted in the identification of the suggested kinetic mechanism. SNIFTIRS confirmed the incorporation of the surfactant into the polypyrrole film and for the first time structural changes within the polymer were observed that could be related to the observed electrochemistry of the polymer.
\end{abstract}

Keywords: Polypyrrole, 1,2-Napthaquinone-4-sulfonic acid, Electropolymerization, Impedance spectroscopy, Conductivity, SNIFTIRS

DOI: 10.1002/elan.200603732

\section{Introduction}

Polypyrrole (PPy) is an intrinsically conducting polymer with various interesting properties $[1,2]$. Its synthesis, characterization, and applications have received a lot of attention in publication over the past two decades but there is still a challenge in the control of synthesis conditions and the nature of dopant ion introduced in order to generate new sensor materials with favorable electrochemistry, morphology, and spectroscopic properties [3-14]. By employing chemical synthesis routes the polypyrrole is mainly produced in the bulk solution and the transfer of the polypyrrole to a suitable electrode surface is limited. Polypyrrole is insoluble in most common solvents and adherence of polypyrrole to the electrode surface during sensor preparation, is also problematic in the absence of suitable dopants that improves its properties. These disadvantages however may be avoided, if electrochemical polymerization is applied [15-21]. Thickness and morphology of the film are easily controlled by type of solvent, electrolyte concentration and type of electrode material, current density, applied potential, polymerization time and temperature [15, 16]. The optimization of these parameters in order to obtain nanostructured and reasonably stable PPy in air and in aqueous media opens the way for entrapment and/or doping of polypyrrole by various biomaterials such as small organic molecules, DNA, proteins and even living cells [17-20]. In particular cases, PPy may be synthesized in the overoxidized state and entrapped molecules may be removed to produce molecularly imprinted polymer electrodes. Electropolymerization also allows the deposition of films independent of the electrochemical cell geometry and this is particularly useful in the design of micro fluidic systems [21].

Surfactants are used as polymer additives in order to control the morphology and when implicitly incorporated into the conducting polymer backbone, it serves to improve the conductivity, stability, solubility in organic solvents and processability [22]. Surfactants affect the preparation of conducting polymers in three ways, i.e., (i) the micelles control the distribution of reactants between the micellar and the aqueous phase and thus exerts some control over the polymerization pathway (ii) anionic surfactants may act as counter ions for the polymer polycations and (iii) the hydrophobic tail of the surfactant may adsorb on the polymer formed at the electrode surface and thus becomes part of the resulting material, influencing its chemical properties [23]. 
We have recently prepared 1, 2-naphthaquinone sulfonic acid doped polypyrrole (PPyNQSA) through potentiodynamic electropolymerization from aqueous solution, at low $\mathrm{pH}$ on a platinum disk electrode to form stable thin films with good electrochemical activity, improved conductivity and visibly different colors on the oxidized state as opposed to the neutral state. By subjecting these films generated in situ, to intensive electrochemical characterization we propose a mechanism to support the unique electrochemistry of the doped polypyrrole films. This paper reports our spectroand electrochemical investigation on the electrosynthesized film, which showed improved properties. These improved properties of the modified polymer material lend itself favorably to applications in fuel cells, chemical sensors, controlled drug delivery, switching based on electrochromic control, corrosion protection, and environmental remediation.

\section{Experimental}

\subsection{Chemicals}

The Pyrrole (98\%) used was supplied by Sigma-Aldrich (Pty) Ltd., South Africa. This was distilled at reduced pressure, saturated with argon gas, and kept in $1-\mathrm{cm}^{3}$ ampoules in the dark at $4{ }^{\circ} \mathrm{C}$. The sodium salt of 1,2 napthaquinone-4-sulfonic acid (BDH laboratory reagent) was used as the dopant. The electrolyte used in the polymerization and all electrochemical characterization experiments was prepared from hydrochloric acid (32\%) (Fluka) and distilled water (specific resistance $18 \mathrm{M} \Omega$, MilliQ, Millipore).

\subsection{Voltammetric Measurements}

Cyclic voltammetric (CV), Osteryoung square wave voltammetry (OSWV) and differential pulse voltammetry (DPV) measurements were made using a BAS 50W integrated automated electrochemical workstation (Bioanalytical Systems, Lafayate, IN, USA). The three electrode cell used contained a platinum disk electrode with a surface area of $0.0201 \mathrm{~cm}^{2}$ as working electrode which was polished to a shiny finish using slurries of $0.3 \mu \mathrm{m}$ and $0.05 \mu \mathrm{m}$ fine alumina powders (Bueller, IL, USA), and rinsed with deionized water. The reference electrode used was Ag/ $\mathrm{AgCl}$ electrode -BAS MF-2052 (3 M NaCl type) and the counter electrode was a polished platinum wire. The electrolyte used in all the electrochemical experiments, was $\mathrm{HCl}$. A thin film of conducting polypyrrole was grown under potentiodynamic conditions from a solution containing the $350-\mu \mathrm{L}$ pyrrole monomer ( 0.0050 moles $)$ and $0.130 \mathrm{~g}$ of the sodium salt of 1, 2-napthaquinone-4-sulfonic aciddopant ( 0.0005 moles) respectively in $50 \mathrm{~mL}$ of $0.05 \mathrm{M} \mathrm{HCl}$. The solution from which the film was generated was then replaced with a fresh electrolyte solution of $0.05 \mathrm{M} \mathrm{HCl}$, in which all cyclic voltammetry experiments were then per- formed. The potential window used for the polymerization and characterization studies was $-400 \mathrm{mV}$ to $700 \mathrm{mV}$ vs. $\mathrm{Ag} / \mathrm{AgCl}$. OSWV were performed at $5 \mathrm{~Hz}$ at $25 \mathrm{mV}$ square wave amplitude using a potential step of $4 \mathrm{mV}$ from an initial potential, $E_{\mathrm{i}}$, of $-400 \mathrm{mV}$ to a final potential, $E_{\mathrm{f}}$, of $700 \mathrm{mV}$. DPV experiments were performed at scan rates of 5,10 and $20 \mathrm{mV}$ at pulse amplitude of $25 \mathrm{mV}$.

\subsection{EIS Measurements}

EIS measurements were performed on the thin film of NQSA-doped polypyrrole from 2.2 using a PGZ402 Voltalab Analyzer (Radiometer Analytical S.A, France) and the same three-electrode cell arrangement and electrolyte as for cyclic voltammetry. An AC amplitude of $10 \mathrm{mV}$ at different applied potentials between 0 and $600 \mathrm{mV}$ at $50 \mathrm{mV}$ intervals, over a frequency range from $10^{5}$ to $10^{-2} \mathrm{~Hz}$ in 20 steps per frequency decade. Data analysis was done by modeling with equivalent electrical circuits using Z-View software.

\subsection{SNIFTIRS}

Subtractively normalized interfacial Fourier transform infrared spectroscopy (SNIFTIRS) measurements were performed in the staircase mode using a fully evacuated FTIR spectrometer (Bruker IFS113v) fitted with a mercury cadmium telluride (MCT) photo detector and $\mathrm{Ge} / \mathrm{KBr}$ beam splitter. The thin film of polypyrrole generated as in 2.2 above was subjected to SNIFTIRS analysis using a custom built thin-layer three-electrode cell. The reflectance data on the film at the working electrode was collected at different applied potential using a manually controlled potentiostat. A calomel reference electrode was used and a platinum ring electrode fitted on the inside of the custom made FTIR electrochemical cell, served as counter electrode [24]. During the in situ measurements of FTIR spectra the surface of the working electrode was positioned very close to the $\mathrm{CaF}_{2}$ window and parallel to it in order to limit the influence of solvent on the spectra. Spectra were obtained at potentials from $0 \mathrm{mV}$ to $600 \mathrm{mV}$ at $100 \mathrm{mV}$ intervals. Spectra were also recorded at selected potentials in the reverse direction as a check on the reversibility of the modified polymer. Spectra were obtained by Fourier transformation after averaging 200 interferograms acquired at each potential, using p-polarized radiation. Infrared spectra have been normalized with respect to the reference spectrum collected at $0 \mathrm{mV}$ and are displayed as $\Delta R / R$ difference spectra (the ratio of the signals obtained at potentials $E_{\mathrm{i}}$ and $E_{\mathrm{ref}}$ and that obtained at the reference potential $\left.E_{\text {ref }}\right)$ in units of reflectance, since no logarithm was applied [25].

Subtractively normalized SNIFTIRS spectra obtained in this way therefore, contain only information of the molecular changes occurring from modification of the oxidation state of the polymer. Negative bands were interpreted as indicative of absorption by species generated as the 
potential is changed to $E_{i}$, while upward peaks were interpreted as the disappearance of initial species [26].

\section{Results and Discussion}

\subsection{Voltammetry}

The potentiodynamic behavior of the modified polypyrrole is shown in Figure 1. The electrochemically-polymerized film, grown at a scan rate of $50 \mathrm{mV} \mathrm{s}^{-1}$ for 25 cycles, was observed to have good adhesion to the Pt electrode surface. It should be noted that the ratio of the mole concentration of the monomer/dopant mixture is critical in order to produce a conducting polymer. A potential window of -400 through $700 \mathrm{mV}$ vs. $\mathrm{Ag} / \mathrm{AgCl}$ was used for the polymerization and investigation after optimization of the synthesis conditions. This optimum range was arrived at based on the overoxidation and degradation of polypyrrole at higher positive potentials, whilst a too negative potential will result in hydrogen evolution [27]. The cyclic voltammograms consistently displayed one distinctive oxidation and one reduction peak. The peak separation between the anodic and cathodic peaks, increased with increase in scan rates. From our multiscan rate voltammograms (Fig. 1), the anodic/ cathodic peak potentials were $364 \mathrm{mV}$ and $301 \mathrm{mV}$ vs. Ag/ $\mathrm{AgCl}$ respectively at $5 \mathrm{mV} \mathrm{s}^{-1}$. The average formal potential $\left(E^{\circ \prime}\right)$ estimated from peak potentials at 5, 10, 15, 25, 30, 40 and $50 \mathrm{mV} \mathrm{s}^{-1}$ was calculated as $322 \pm 5 \mathrm{mV}$. DPV investigation at a scan rate of $5 \mathrm{mV} \mathrm{s}^{-1}$ gave both anodic and cathodic peaks at $317 \mathrm{mV}$ while the OSWV at a frequency of $15 \mathrm{~Hz}$ and amplitude of $25 \mathrm{mV}$ gave a formal potential $\left(E^{\circ \prime}\right)$ value of $317 \mathrm{mV}$. The $\mathrm{CV}$ peak separation of $63 \mathrm{mV}$ at $5 \mathrm{mV}$ $\mathrm{s}^{-1}$ was used as an indication of a one electron process for the polymer.

The Brown Anson equation, $\left\{I_{\mathrm{p}}=n^{2} F^{2} \Gamma^{*}{ }_{\text {PPyNQSA }} A v / 4 R T\right\}$, was used to estimate the surface concentration of the polymer $\left(\Gamma^{*}{ }_{\mathrm{PPyNOSA}}\right)$ using the peak currents $\left(I_{\mathrm{p}}\right)$ obtained at different scan rates $(v)$ between $5 \mathrm{mV} \mathrm{s}^{-1}$ and $50 \mathrm{mV} \mathrm{s}^{-1}$ [28].

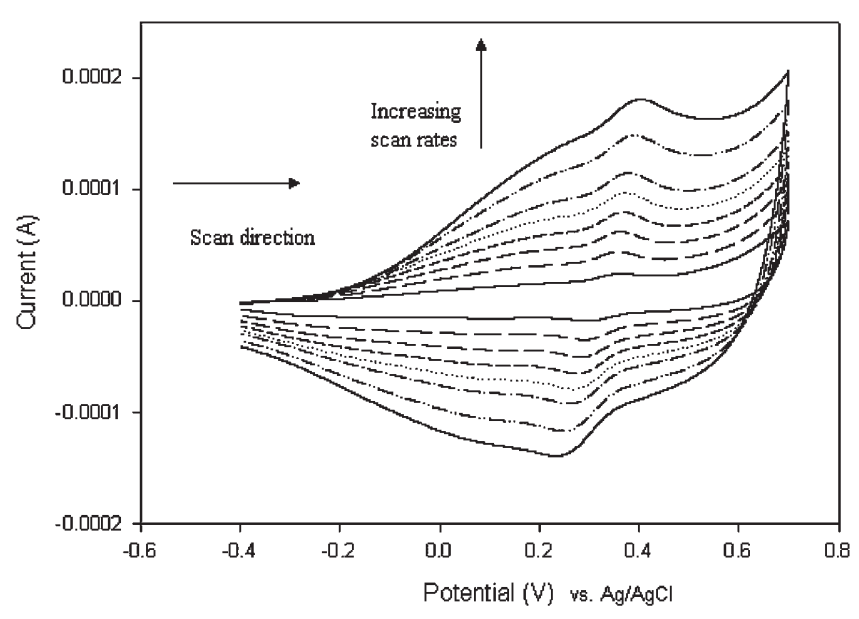

Fig. 1. Multiscan rate voltammograms obtained at a modified platinum electrode with a thin film of PPyNQSA in $0.05 \mathrm{M} \mathrm{HCl}$ at scan rates of $5,10,15,20,25,30,40$, and $50 \mathrm{mV} \mathrm{s}^{-1}$.
The notations $F, A, R$ and $T$ are constants for the Faraday's constant $\left(96584 \mathrm{C} \mathrm{mol}^{-1}\right.$ ), working electrode area, molar gas constant and room temperature of $298 \mathrm{~K}$ respectively. The plots gave a trend that confirms the formation of a stable film whose density is slightly lower during reduction $(1.42 \times$ $\left.10^{-7} \mathrm{~mol} \cdot \mathrm{cm}^{-2}\right)$ as compared to oxidation $\left(1.83 \times 10^{-7} \mathrm{~mol}\right.$. $\mathrm{cm}^{-2}$ ). The plots showed linear relationship with correlation coefficient $\left(r^{2}\right)$ of 0.999 and 0.994 respectively for the anodic and cathodic currents vs. scan rates. The ratio of anodic peak current $\left(I_{\mathrm{p}, \mathrm{a}}\right)$ to cathodic peak current $\left(I_{\mathrm{p}, \mathrm{c}}\right)$ ranged from 1.23 to 1.38 over the range of scan rates applied, which is not exactly unity as required for fully reversible one electron transfer, and therefore a quasireversible electron transfer mechanism is suggested.

The systems displayed progressive shift in anodic peak potential towards more positive values coupled with shift in cathodic peak potential to less positive values with increase in scan rate. The separations increase progressively from $63 \mathrm{mV}$ at $5 \mathrm{mV} \mathrm{s}^{-1}$ to $166 \mathrm{mV}$ at $50 \mathrm{mV} \mathrm{s}^{-1}$ coupled with increase in the magnitude of the peak currents with increase in scan rates. This shows that the peak currents are diffusion controlled. Thus the Randel-Sevcik equation $\left\{I_{\mathrm{p}} / v^{1 / 2}=\right.$ $\left.2.686 \times 10^{5} n^{3 / 2} A \Gamma^{*}{ }_{\text {PPyNOSA }} D_{\mathrm{e}}^{1 / 2}\right\}$ was applied to determine the diffusion coefficient $\left(D_{\mathrm{e}}\right)$ for electron hopping along the polymer chain [29]. $I_{\mathrm{p}}$ is the peak current in $\mathrm{A}, \mathrm{n}$ is the number of electron transferred, $v$ is the scan rate in $\mathrm{V} \mathrm{s}^{-1}, \mathrm{n}$ is the no of electrons transferred, $A$ is the surface area of the electrode $\mathrm{cm}^{2}, \Gamma^{*}{ }_{\mathrm{PPyNOSA}}$ is the surface concentration of the polymer film in mol $\mathrm{cm}^{2}, D_{\mathrm{e}}$, is the rate a charge transportation in $\mathrm{cm}^{2} \mathrm{~s}^{-1}$ along the polymer chain. The slopes of the linear plots are 1.0309 and $0.8025 \mathrm{~A} /(\mathrm{V} / \mathrm{s})^{1 / 2}$ for the oxidation and reduction scan waves with a corresponding correlation coefficient of 0.981 and 0.991 respectively. $D_{\mathrm{e}}$, indicating the rate of electron transfer along the polymer chain, was found to be the same for the oxidation and reduction reaction, i.e., $1.02 \times 10^{-6} \mathrm{~cm}^{2} \mathrm{~s}^{-1}$. This suggests that the deviation from full reversibility does not necessarily involve permanent electronic changes to the bulk polypyrrole film upon potential cycling, but that some other phenomenon is responsible for the kinetics observed.

The cyclic voltammogram at a scan rate of $5 \mathrm{mV} \mathrm{s}^{-1}$ was used to investigate the rate constant $\left(k^{0}\right)$ for electron transfer within the polymer chain using Nicholson treatment for a quasireversible electrochemical system using the equation $\left\{k^{0}=\varphi\left(\alpha n F \vee D_{\mathrm{e}} / R T\right)^{1 / 2}\right\}[29-31]$.

The diffusion coefficient $\left(D_{\mathrm{e}}\right)$ is in $\mathrm{cm}^{2} \mathrm{~s}^{-1}$; molar gas constant $(R)$ is in $\mathrm{J} \mathrm{mol}^{-1} \mathrm{~K}^{-1}$; Faraday's constant $(F)$ in $\mathrm{C}$ and temperature $(T)$ being in $\mathrm{K}$. The transfer coefficient, $\alpha$, of 0.5 was assumed for the PPyNQSA systems and the kinetic parameter, $\varphi$ (dimensionless), was assigned a value of 7 based on the peak separation, $\Delta E_{\mathrm{p}}$, of $63 \mathrm{mV}$ at a scan rate of $5 \mathrm{mV} \mathrm{s}^{-1}$ which indicated $n=1.1$. The $k^{0}$ value of $2.20 \times 10^{-3} \mathrm{~cm} \mathrm{~s}^{-1}$ obtained for the polymer at $5 \mathrm{mV} \mathrm{s}^{-1}$ shows that electron hopping along the polymer chain at the low scan rate is quite facile. This is comparable with the rate constants reported for other conducting polymers vis. $\mathrm{Pt} /$ polyaniline electrodes with $k^{0}$ values of 0.049 to $5.4 \times 10^{-3}$ $\mathrm{cm} \mathrm{s}^{-1}$ in different electrolytes [32] and Pt/ poly(3,4-ethyl- 
enedioxythiophene) electrodes with $k^{0}$ values of 1.5 to $45.3 \times 10^{-3} \mathrm{~cm} \mathrm{~s}^{-1}$ when prepared under different synthesis conditions [33].

\subsection{Impedance Spectroscopy}

Electrochemical impedance spectroscopy (EIS) enables the separation of interfacial electron transfer from concomitant electronic changes occurring within the bulk material of the electrode on the basis of frequency dependent electrochemical response. EIS data was collected, in consecutive $50 \mathrm{mV}$ steps, in the potential range corresponding to the oxidation of the polymer film $(0 \mathrm{mV}$ to $600 \mathrm{mV})$ and the subsequent reduction by inversion of the steps in potential back to $0 \mathrm{mV}$.

Typical data obtained at an applied potential of $+50 \mathrm{mV}$ vs. $\mathrm{Ag} / \mathrm{AgCl}$ are shown in the complex plane impedance plots of Figure 2. The data obtained was analyzed using an equivalent electrical circuit consisting of the solution resistance $\left(R_{\mathrm{s}}\right)$, an $R_{1} C P E_{1}$ parallel combination, where $C P E$ is a constant phase element, to model movement by electron hopping through the polymer film along the polymer backbone, and a second $R_{2} C_{2}$ component in series representing the electrode /solution interface, as indicated in $[34,35]$. The CPE was modeled as a nonideal capacitance, according to

$C P E=1 /(C i \omega)^{n}$

The $C P E$ is defined by two values, i.e., the capacitance, $C$, and the $C P E$ exponent, $n$, which has a value between 0.5 and

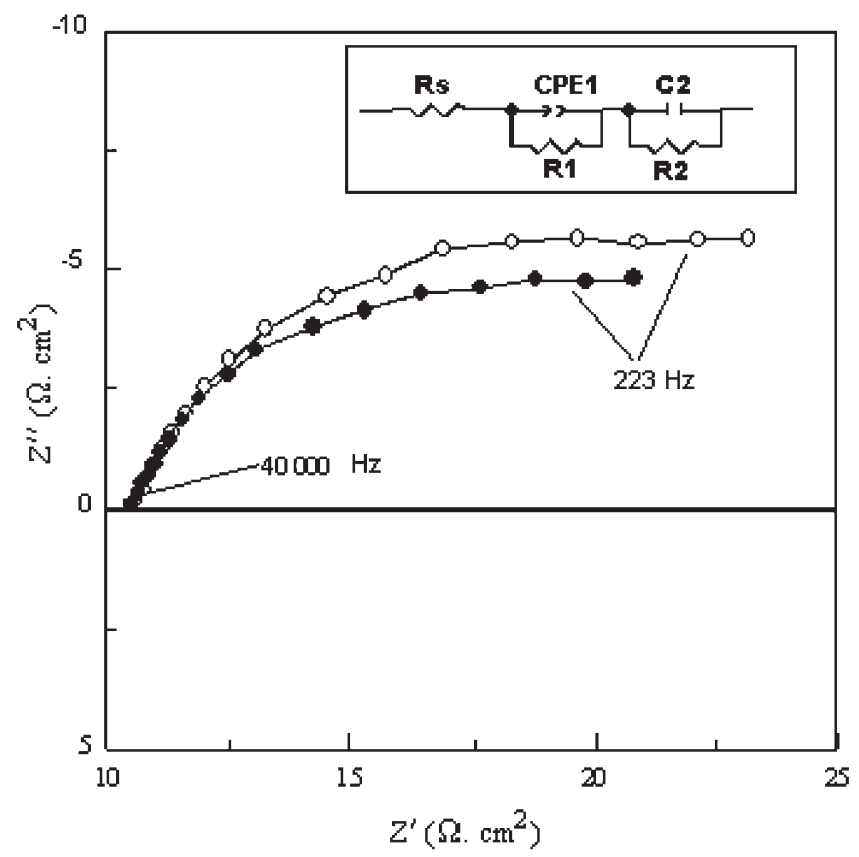

Fig. 2. Complex plane impedance plots of PPyNQSA thin film electrode at $50 \mathrm{mV}$ vs. $\mathrm{Ag} / \mathrm{AgCl}$ in $0.05 \mathrm{M} \mathrm{HCl}$ during (•) step-bystep oxidation and $(\bullet)$ subsequent reduction (insert is the equivalent circuit used to fit the data).
1 for a nonideal capacitor. If $n$ equals 1 , the equation is identical to that of a capacitor and smaller values can be related to surface roughness and inhomogeneities, which lead to frequency dispersion. When a $C P E$ is placed in parallel to a resistor, a depressed semicircle (Cole-element) is produced. The solution resistance varied from 9.6 to $11.0 \Omega$. The values of $R_{1}$ and $C P E_{1}$ were interpreted through the electrical characteristics of the electropolymerized PPyNQSA polymer bulk material. The capacitive nature of the bulk material was substantiated by the inverse relationship between the capacitance and resistance values of the high frequency loop. The polymer material showed good conductivity $(10-20 \Omega)$ and in the region of the formal potential as obtained by voltammetric experiments, the conductivity of the polymer material was measured as $10.8 \Omega$. The average value of $n$ for all experiments was 0.56 , which is indicative of a rather rough morphology and porous structure and is probably also associated with electron hopping along the polymer backbone. The interface of the polymer with the $\mathrm{HCl}$ electrolyte showed consistently low values of capacitance, $C_{2}(30 \mu \mathrm{F})$ and resistance, $R_{2}(2.7-$ $4.2 \Omega$ ) during the oxidation steps, the latter reaching a minimum value of $2.7 \Omega$ at the formal oxidation potential. The electron transfer from solution to the polymer film during oxidation is thought to be direct electron transfer without mediation by any surface bound species, since the interfacial capacitance values of $16 \mu \mathrm{F}$ hardly varied over the potential range studied.

During the subsequent reduction steps, from $600 \mathrm{mV}$ to $0 \mathrm{mV}$ vs. $\mathrm{Ag} / \mathrm{AgCl}$, the capacitance $(2 \mathrm{mF})$ and the resistance $(15.5 \Omega)$ of the polymer bulk material remained fairly constant. The bulk capacitance $\left(C P E_{1}\right)$ and resistance $\left(R_{1}\right)$ values were of the same order of magnitude during the reduction steps as compared with oxidation. However, a plot of the interfacial capacitance $\left(C_{2}\right)$ versus applied potential showed a gradual increase in capacitance as the potential became more negative, and gradual increase as it became more positive (Fig. 3). The capacitance values for

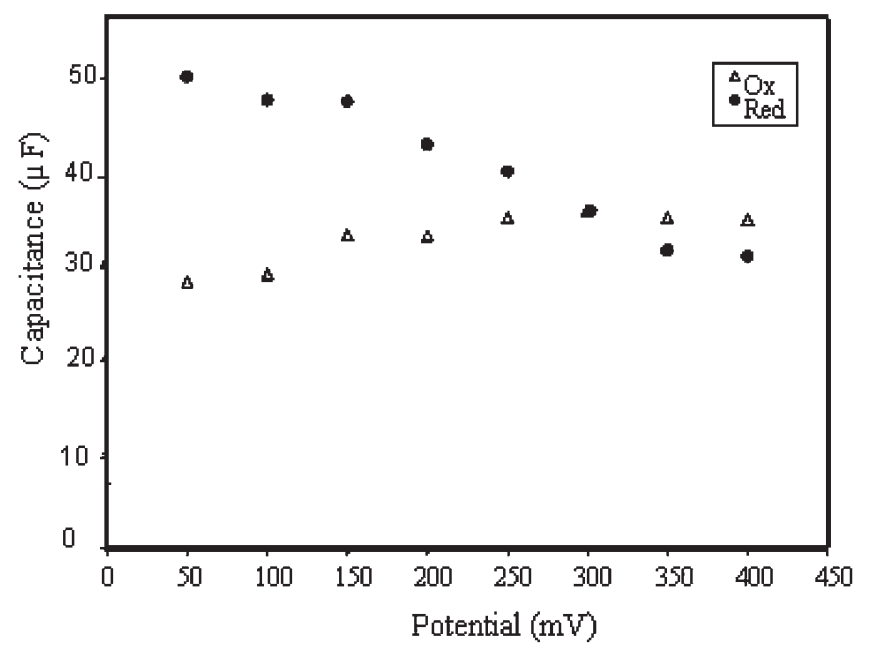

Fig. 3. Plot of interfacial capacitance versus potential for the oxidation and reduction of the PPyNQSA thin film. 
the oxidation and reduction trend intersect in the region of the formal potential $(300 \mathrm{mV})$.

This trend suggests a disruption to the direct electron transfer kinetics observed during oxidation. Evidence from SNIFTIRS suggests degradation of surface bound polymer units by anions in solution (e.g., $\mathrm{Cl}^{-}$) which results in ring opening of surface polymer units and eventual loss of $\mathrm{CO}_{2}$, similar to the structural degradation induced in pyrrole under strongly basic conditions [26]. This surface chemistry could explain the observed changes in EIS data and confirms the quasireversible oxidation kinetics predicted by the scanrate-dependent $\mathrm{CV}$. The difference between the complex plane impedance plots at $50 \mathrm{mV}$ before oxidation and after reduction (Fig. 2) is further evidence of this.

\subsection{SNIFTIRS}

A shift of the baseline was evident in the spectra obtained at potentials increasingly positive of $0 \mathrm{mV}$, when the spectra were viewed over the extended scale, covering the complete wavenumber range experimentally available, i.e., $5000 \mathrm{~cm}^{-1}$ to $1000 \mathrm{~cm}^{-1}$ (Fig. 4). This is related to low energy transitions within the polymer and is evidence of the conductive nature of the modified polymer. The solvent features seen at around $3500 \mathrm{~cm}^{-1}$ were not expected to interfere with other absorptions. During the analysis of spectral data however emphasis was placed on the absorptions between $1700 \mathrm{~cm}^{-1}$ to $1000 \mathrm{~cm}^{-1}$, known as the fingerprint region of the spectrum. The intensity of absorption bands present in this region is indicative of the oxidation state of the polymer.

The bands present in the region of ring stretching are particularly intense due to strong coupling between charge carriers and ring vibrational modes, facilitating movement of carriers within conjugated polymer chains. These enhanced signals (IRAV bands) are typical of doped conducting polymers. The vibrations occur as paired bands at very close frequencies. The downward bands at 1531 and $1586 \mathrm{~cm}^{-1}$ were assigned to $\mathrm{C}=\mathrm{C}$ and $\mathrm{C}-\mathrm{C}$ vibrations. The bands at 1432 and $1380 \mathrm{~cm}^{-1}$ are assigned to $\mathrm{C}=\mathrm{N}$ vibration. The band at $1294 \mathrm{~cm}^{-1}$ was assigned to $\mathrm{N}-\mathrm{H}$ in plane contributions. Evidence of the sulfonic acid presence in the doped polymer was provided by the absorption bands at 1172 and $1080 \mathrm{~cm}^{-1}$, assigned to the asymmetric stretch of the $\mathrm{O}=\mathrm{S}=\mathrm{O}$ group (Fig. 5) [36-39].

An absorption band at $2340 \mathrm{~cm}^{-1}$ which increased in intensity at potentials above $300 \mathrm{mV}$, is indicative of the presence of $\mathrm{CO}_{2}[39-40]$.

\subsection{Polymer Structure and Proposed Mechanism}

During the first cycle of electrochemical polymerization of pyrrole an inner layer is formed upon which the polymerized polypyrrole grows. Subsequent cycling steps allow for the development of the polymer chain resulting in the main layer and the thickness thereof depends on the number of potential cycles employed. It is also the main layer that

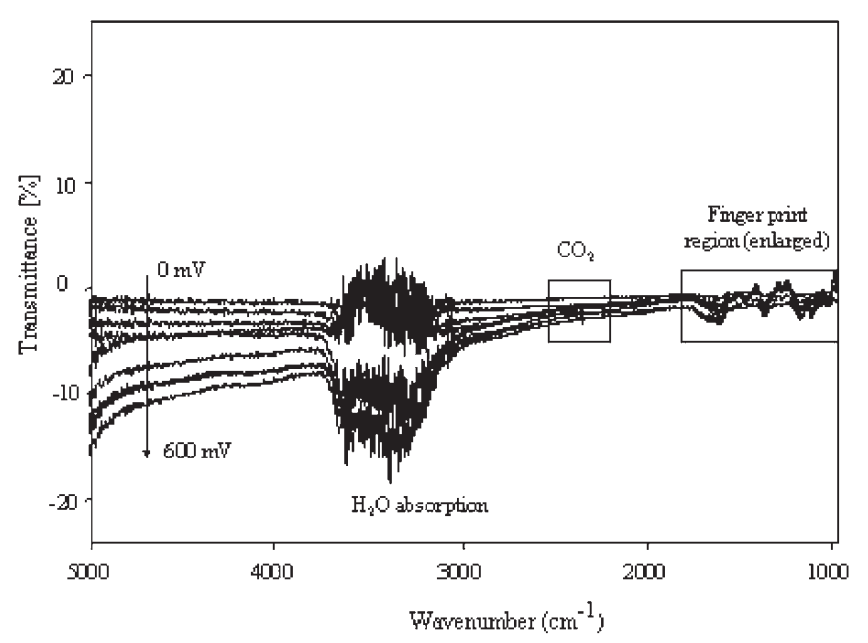

Fig. 4. Full SNIFTIRS spectra of PPyNQSA at $100 \mathrm{mV}$ potential intervals from 0 to $600 \mathrm{mV}$, vs. calomel electrode.

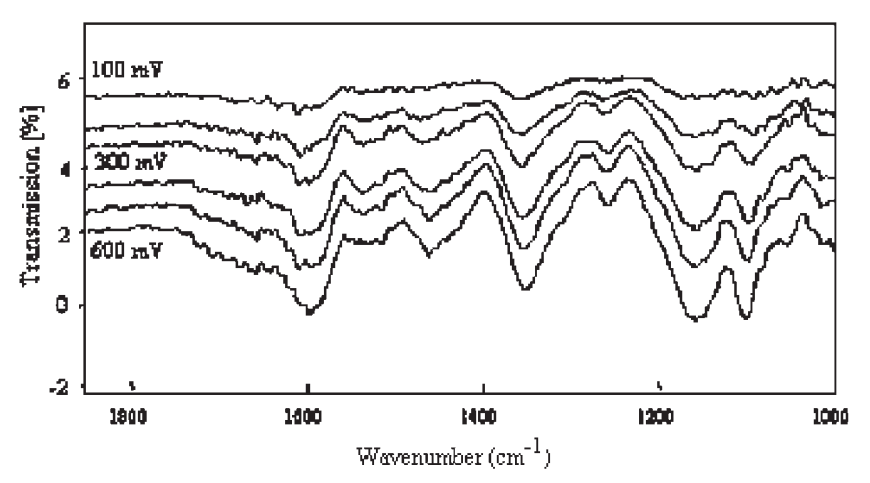

Fig. 5. Normalized SNIFTIRS spectra of PPyNQSA showing the enlargement of the finger print region.

influences overall film stability. The outer layer is produced by polymer termination when the potential is turned off and is made up of mainly short chain polypyrrole and therefore less stable than the main layer (Fig. 6a). When the polypyrrole film is oxidized at $315 \mathrm{mV}$ (vs. $\mathrm{Ag} / \mathrm{AgCl}$ ) the surfactant anions $\left(\mathrm{A}^{-}\right)$align close to the polymer surface to compensate for the positive charge caused by the formation of bipolarons under anodic potentials (Fig. 6b). This phenomenon is sometimes referred to as electroneutrality coupling and results in electron hopping within the polymer main layer to accommodate the bipolaron/ anion coupling at the surface [41].

While actuating the polymer in monomer free $0.05 \mathrm{M}$ $\mathrm{HCl}$, the entrapped 1, 2-napthaquinone-4-sulfonate $\left(\mathrm{NQS}^{-1}\right)$ anion is immobile, it does not move and ionic transport is strictly determined by the hydrated small proton. However, with prolonged actuation or overoxidation, there is breakdown of the surface bound pyrrole and sulfonated units. The surfactant anion, $\mathrm{NQS}^{-1}$, which is formed upon dissociation in the electrolyte behaves as a weak base. The surface bound pyrrole units loose the protons on the nitrogen in order for the surfactant to return to the preferred acidic state. The loss of the proton on the 

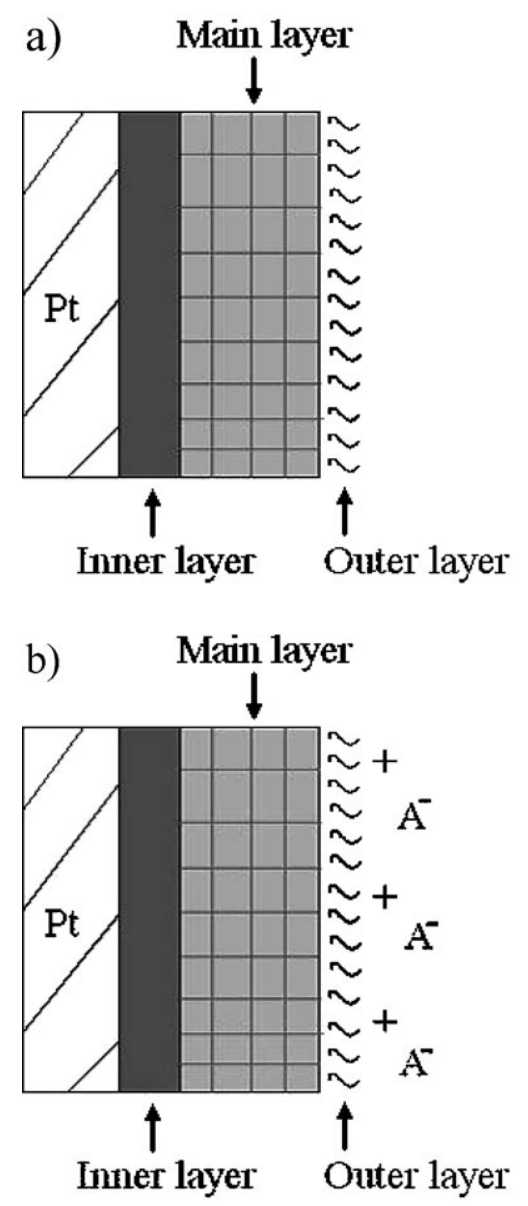

Fig. 6. Model illustrating the alignment of charges at different oxidation states of polypyrrole: a) neutral polymer and b) oxidized polymer.

pyrrole rings however leads to disruption of the cyclic structure by rearrangement to form hydroxyl and carbonyl species and eventual loss of material through formation of $\mathrm{CO}_{2}$ [39].

This suggests that some pyrrole units on the surface of modified polypyrrole chain undergoes ring opening [26]. The lone pair on the ring nitrogen combined with the four $\pi$ electrons of the two double bonds to give pyrrole an aromatic sextet of electrons. The nitrogen is $\mathrm{sp}^{2}$-hybridised and acquires a positive charge as its lone pair is delocalized around the ring $[42,43]$. Therefore we propose a mechanism for the oxidation of the polymer, which involves adsorption of the surfactant onto the polypyrrole film on the electrode surface. The interaction of the surfactant anion with the strongly polarized surface pyrrole units on the polymer backbone leads to disruption of the induced aromaticity on the pyrrole. This results in the protonation of the surfactant to yield the sulfonic acid and deprotonation of the ring nitrogen. Further overoxidation in the acid medium favors the reduction of the double bond adjacent to the nitrogen, which leads to ring opening and subsequent rearrangement to produce the more stable imine structure. The oxidation is irreversible and subsequent electronic rearrangement trans- forms slowly to yield the capacitive material observed under reduction conditions at around $200 \mathrm{mV}$ vs. $\mathrm{Ag} / \mathrm{AgCl}$.

\section{Conclusions}

1, 2-Napthaquinone-4-sulfonate have been successfully incorporated into the matrix of polypyrrole on a platinum disc electrode through potential cycling in aqueous solution of pyrrole-monomer $(0.1 \mathrm{M})$ and the sodium salt of 1,2 napthaquinone-4-sulfonic acid-dopant $(0.01 \mathrm{M})$ in $0.05 \mathrm{M}$ $\mathrm{HCl}$. The resulting polymer showed high conductivity, optical changes, spectroscopic transitions and good electroactivity. The high frequency response of the modified polymer could not display a complete semicircle expected for in the complex impedance plot due to the limitation of the instrument that can not accumulate impedance data above $100 \mathrm{kHz}$. However the low frequency response shows a gradual transition of the volumetric capacitance with potential under oxidative potential stepping, whereas the reductive stepping gave an irreversible trend as the polymer do not revert to the low frequency impedance during the oxidative stepping. There was good correlation of data between the electrochemical and spectroelectrochemical investigation on the modified polymer using cyclic voltammetry, differential pulse voltammetry, square wave voltammetry, electrochemical impedance spectroscopy and SNIFTIRS. There was smooth transition from the neutral to the polaronic and bipolaronic states as it is switched through a potential window of -400 through $700 \mathrm{mV}$ vs. $\mathrm{Ag} / \mathrm{AgCl}$. It is worth noting that the NQSA doped polypyrrole showed strong emissions in aqueous dispersion, which provides indication of potential applications in fabrication of various optometric devices. The application of this modified polypyrrole for biosensors and chemosensors is being investigated.

\section{Acknowledgements}

The authors are grateful to the National Research Foundation (NRF) of South Africa, Focus Area Research Grant and Mobility Grant for the work reported in this paper. We also wish to thank our colleagues in the research laboratories where this work was carried out for their valuable input, i.e., ICEMS (Research Unit 03), Coimbra, Portugal and the electrochemistry group, University of Wales, Bangor, UK.

\section{References}

[1] L. Qu, G. Shi, J. Yuan, G. Han, F. Chen, J. Electroanal. Chem. 2004, 561, 149.

[2] J. Bobacka, Electroanalysis 2005, 18, 7.

[3] R. O. Akinyeye, M. Sekota, P. Baker, E. Iwuoha, Fullerenes, Nanotubes and Carbon Nanostructures 2006, 14, 49.

[4] Y. Yang, J. Liu; M. Wan, Nanotechnology 2002, 13, 771.

[5] A. Kassim, Z. B. Basar, H. N. M. E. Mahmud, Proc. Indian Acad. Sci (Chem. Sci.) 2002, 114, 155. 
[6] Z. Wei, Z. Zhang, M. Wan, Langmuir 2002, 18, 917.

[7] J. Y. Lee, D. Y. Kim, C. Y. Kim, Synth. Met. 1995, 74, 103.

[8] R. Turcu, R. Grecu, M. Brie, I. Peter, A. Bot, W. Graupner, Studia universitatis babes-bolyai, Physica, special issue 2001, 216.

[9] S. Asavapiriyanont, G. K. Chandler, G. A. Gunawardena, J. Electroanal. Chem. 1984, 177, 229.

[10] H. Masunda, D. K. Asano, Synth. Met. 2003, 135-136, 43.

[11] F. Cheng, M. Zhang, H. Wang, Sensors 2005, 5, 245.

[12] H. Shiigi, M. Kishimoto, H. Yakabe, B. Deore, T. Nagooka, Anal. Sci. 2002, 18, 41.

[13] Y. Lu, A. Pich, H. Adler, Synth. Met. 2003, 135-136, 37.

[14] T. K. Vishnuvardhan, V. R. Kulkarni, C. Basavaraja, S. C. Raghavendra, Bull. Mater. Sci. 2006, 29, 77.

[15] M.-A. Paoli A. Zanelli, M. Mastragostino, A. M. Rocco, J. Electroanal. Chem. 1997, 435, 217.

[16] D. Han, H. J. Lee, S. Park Electrochim. Acta 2004, 50, 3085.

[17] J. Wang, Chem. Eur. J. 1999, 5, 1681.

[18] J. Wang, M. Jiang, Langmuir 2000, 16, 2269.

[19] A. Ravanaviciene, A. Ravanavicius, Anal. Bioanal. Chem. 2004, 379, 287.

[20] B. D. Malhorta, A. Chaubey, S. P. Singh, Anal. Chim. Acta, doi: 10.1016/j.aca.2006.04.055.

[21] A. Ramanavičious, A. Ramanavičienè, A. Malinaukas, Electrochim. Acta 2006, in press.

[22] A. A. Yakovleva, Rus. J. Electrochem. 2000, 36, 1275.

[23] J. Stejskal, M. Omastová, S. Fedorova, J. Prokeš, M. Trchová, Polymer 2003, 44, 1353.

[24] A. S. Viana, L. M. Abrantes, G. Jin, S. Floate, R. J. Nicholas, M. Kalaji, PhysChemChemPhys 2001, 3, 3411.

[25] Y. Martínez, R. Hernandez, M. Kalaji, O. P. Márquez, J. Márquez. J. Electroanal. Chem. 2004, 563, 145.

[26] H. Xie, M. Yan, Z Jiang, Electrochim. Acta 1997, 42, 2361.

[27] E. Smela, J. Micromech. Microeng. 1999, 9, 1.
[28] A. P. Brown, F. C. Anson, Anal. Chem. 1977, 49, 1589.

[29] A. J. Bard, L. R. Faulkner, Electrochemical Methods Fundamentals and Applications, 2nd ed., Wiley, New York 2001, pp. 239-256.

[30] R. S. Nicholson, Anal. Chem. 1965, 37, 1351.

[31] P. Zanello, Inorganic Electrochemistry (Theory, Practice and Applications), Royal Society of Chemistry, Cambridge, UK, 2003, pp. 49-135.

[32] R. Pauliukaite, C. M. A. Brett, A. P. Monkman, Electrochim. Acta 2004, 50, 159.

[33] F. Sundfors, J. Bobacka, A. Ivaska, A. Lewenstam, Electrochim. Acta 2002, 47, 2245.

[34] M. Grzeszczuk, G. Żabińska-Olszak, J. Electroanal. Chem. 1997, 427, 169.

[35] P. J. Mahon, G. L. Paul, S. M. Keshishian, A. M. Vassallo, J. Power Sources 2000, 91, 68.

[36] A. Benyoucef, F. Huerta, J. L. Vázquez, E. Morallon, Europ. Polymer J. 2005, 41, 843.

[37] R. T. S. M. Lakshmi, M. K. Vyas, A. S. Brar, I. K. Varma, Europ. Polymer J. 2006, 42, 1423.

[38] A. K. Cuentas-Gallegos, P. Gomez-Romero, J. New Mater. Electrochem. Systems 2005, 8, 181.

[39] I. Rodríguez, B. R. Scharifker, J Mostany, J. Electroanal.Chem. 2000, 491, 117.

[40] D. J. Fermín, H. Teruel, B. R. Scharifker, J. Electroanal. Chem. 1996, 401, 207.

[41] Y. J. Yuan, S. B. Aduloju, G. G. Wallace, Europ. Polymer J. 1998, 35, 1761.

[42] R. T. Morrison, R. N Boyd, Organic Chemistry, 15th ed., Allyn and Bacon, New York University, USA 1980, pp. $1002-1026$.

[43] G. M. Loudon, Organic Chemistry, Benjamin/Cummins, California, USA 1988, pp. 1043-1090. 